\title{
SURGICAL EXPOSURE OF A UNILATERAL IMPACTED MANDIBULAR CANINE FOLLOWED BY ORTHODONTIC EXTRUSION: A CASE REPORT.
} Thakur $\mathrm{H}^{1}$, Jonathan $\mathrm{PT}^{1}$, Galhotra $\mathrm{V}^{2}$, Neha ${ }^{3}$

1Postgraduate student,

1 Postgraduate student,

2Professor and HOD,

3 Reader,

Department of Pedodontics and

Preventive Dentistry, Maharaja

Ganga Singh Dental College and

Research Centre, Sri Ganganagar.

\begin{abstract}
Impacted teeth are those with a delayed eruption time or that are not expected to erupt completely based on clinical and radiographic assessment. Impaction of the permanent third molar teeth is a common clinical occurrence. There are several etiologic factors for canine impactions have been proposed - primary reasons are long path of eruption and genetic influence. The maxillary canine is developing high into the palate with a tortuous course of its eruption path and the mandibular canine is also developing at the lower border of the mandible which might lead to its impaction. In the case presented here, we performed surgical exposure of the impacted canine followed by orthodontic extrusion of the same to its proper alignment in the arch. A 10 -year-old female child came to the Department of Pedodontics for routine dental check-up. On intra - oral examination, the mandibular left lateral incisor was found rotated and there was spacing between the central incisor and lateral incisor. On radiographic examination it was revealed that there was ectopic eruption of the lower left permanent canine with its crown almost overlapping the root of the lateral incisor of same side. The management of impacted canines is important in terms of aesthetics and function. Clinicians must formulate treatment plans that are in the best interest of the patient and they must be knowledgeable about the variety of treatment options.
\end{abstract}

Key words: Impacted canine, ectopic eruption

\section{INTRODUCTION}

Impacted teeth are those with a delayed eruption time or that are not expected to erupt completely based on clinical and radiographic assessment ${ }^{1}$. Impaction of the permanent third molar teeth is a common clinical occurrence. All teeth can be impacted, however, third molars, maxillary canines, mandibular second premolars and maxillary central incisors are the teeth most frequently involved ${ }^{2}$. The prevalence of impacted third molars are $16.7 \%-68.6 \%$ and maxillary canines impaction is $0.9-2.2 \%$ [D'Amico et al., 2003; Aydin et al., 2004; Rohrer, 1929] ${ }^{3-5}$. The impaction of the mandibular canine is less frequent, and the prevalence of impacted mandibular permanent canines ranges only 0.05-0.4\% [Mead, 1930; Yavuz et al., 2007; Sham et al., 1978; Brown et al., 1982 $J^{6-9}$. In this case-report we described a rare condition of impacted mandibular canine of a child in the mixed dentition period.

There are several etiologic factors for canine impactions have been proposed - primary reasons are long path of eruption and genetic influence ${ }^{10}$. The maxillary canine is developing high into the palate with a tortuous course of its eruption path and the mandibular canine is also developing at the lower border of the mandible which might lead to its impaction. The genetic influence of canine impaction was studied by various authors and found genetic involvement in canine impaction. However, females are found to be more affected with canine impaction? (Because $\mathrm{x}$ chromosome is involved). In cases of cleft lip and palate, the maxillary canine tends to erupt through the cleft or it may get impacted. The supernumerary tooth or tooth fragments of primary tooth may also cause impaction of permanent canine although supernumerary teeth mostly cause impaction of permanent incisors. Ectopic eruption path and thick palatal mucosa can contribute to impaction of maxillary canine. Endocrinologic deficiency may also be a contruting factor in some cases with canine impaction but it is also more likely to cause generalized impaction or delayed eruption of all the teeth $^{11}$.

The other factors are the arch length tooth size discrepancy where jaw size is smaller than the tooth material may cause impaction of canine. In cases of absence of maxillary lateral incisor, \{due to congenital missing tooth $\}$ there is loss of guidance for the canine ${ }^{12-14}$. If there is retained primary canine or premature loss of primary canine will also cause impaction of permanent canine. Trauma to the primary canine may sometimes 
cause dilaceration of the permanent canine leading to impaction ${ }^{15,16}$.

Although usually asymptomatic, the situation represents functional, aesthetics, orthodontics and surgical problems. After diagnosis, four types of stances are possible, facing impaction or missing eruption of teeth: abstention (mandibular canines close to the alveolar nerve); extraction; etiologic therapy if a deciduous tooth blocks the evolution; surgical exposure ${ }^{17}$.

In the case presented here, we performed surgical exposure of the impacted canine followed by orthodontic extrusion of the same to its proper alignment in the arch.

\section{CASE REPORT}

A 10 -year-old female child came to the Department of Pedodontics for routine dental check-up. On intra - oral examination, the mandibular left lateral incisor was found rotated and there was spacing between the central incisor and lateral incisor. On radiographic examination it was revealed that there was ectopic eruption of the lower left permanent canine with its crown almost overlapping the root of the lateral incisor of same side (Fig-1).

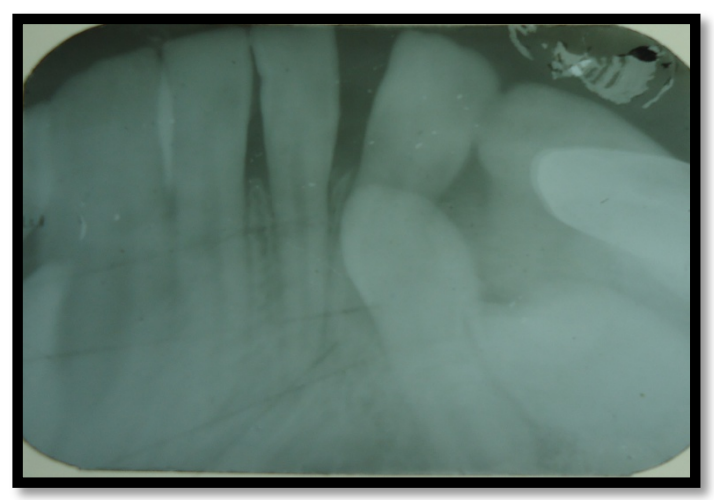

Figure 1: Preoperative IOPA showing ectopically erupting canine on lower left side

More than two third of the root formation has been completed and there is less possibility for the tooth to erupt on its own. So we had planned to expose the tooth surgically followed by orthodontic extrusion. An OPG was taken for the record purpose (Fig-2). The goals of treatment for the patient were to expose the impacted mandibular left canine and then bring it into the dental arch, to level and align the dental arches.

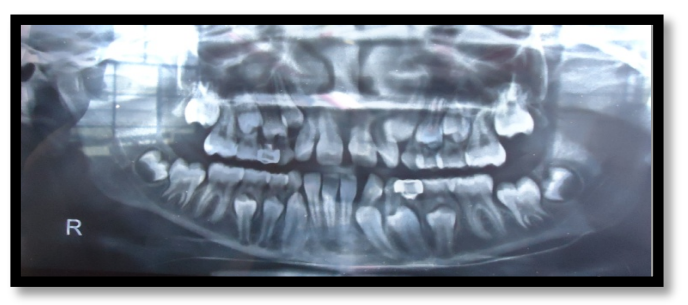

Figure 2: Preoperative Orthopantomogram showing the ectopically erupting canine on

\section{lower left side}

Both lower first permanent molars were banded \& brackets were placed on right mandibular primary canine, permanent lateral and central incisor, left mandibular permanent central and lateral incisor (Fig-3).

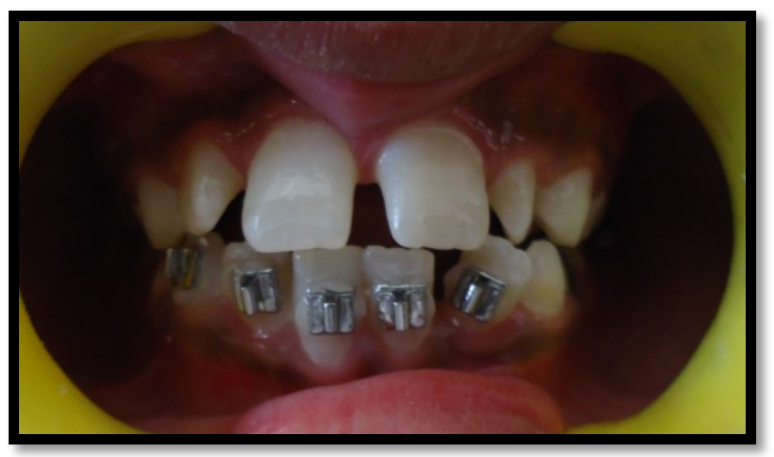

Figure 3: Photograph after bracket placement

One week later surgical exposure of the impacted canine was planned and under aseptic conditions. Left inferior alveolar nerve block was administered using $2 \%$ Lignocaine with adrenaline. The impacted mandibular left canine was exposed surgically and the muco-periosteal flap was reflected just enough to expose the crown of the tooth (Fig-4). The exposed crown of impacted canine was etched, bonded and a orthodontic bracket was placed under proper isolation (Fig-4). After this procedure, extraction of retained primary lower left canine (73) was done followed by suture placement. Post-surgical instructions were given and necessary antibiotics and analgesics were prescribed. Patient was recalled after a week for suture removal.

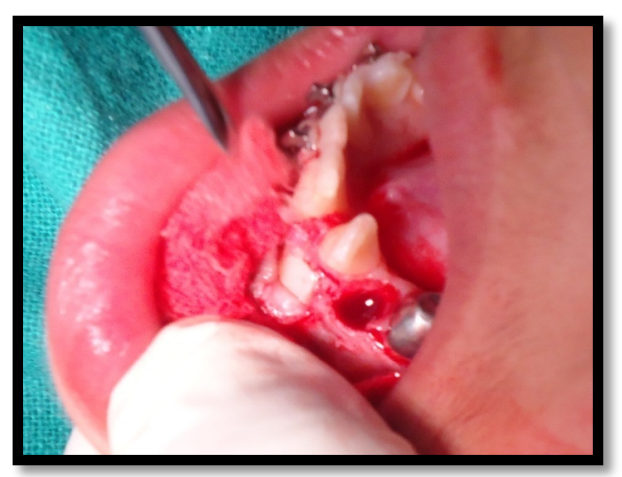

Figure 4: Photograph showing the impacted ectopically erupting canine after flap reflection

An uneventful healing was observed at recall visit and sutures were removed ater 7 days. Orthodontic force was applied immediately by ligating the bracket with 0.009 ligature wire to 0.016 round $\mathrm{Ni}$ - 
Ti to pull the canine. Then, to move the crown of the canine away from the apex of the root of the lateral incisor, distal and upward traction was applied to the canine, using an elastic chain hooked from the bracket on the canine to the buccal tube of the left molar band (Fig-5).

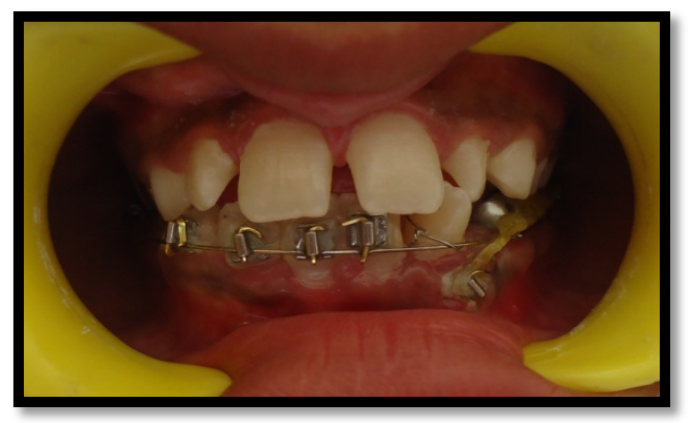

Figure 5: Photograph showing orthodontic extrusion of impacted canine

Over the next 6 months, the progress of canine eruption was evaluated monthly. No complications were observed at the surgical site, and the gingiva remained healthy. Once sufficiently erupted, the crown of the impacted canine was rebonded with a canine bracket to finish the occlusion. (Fig-6)

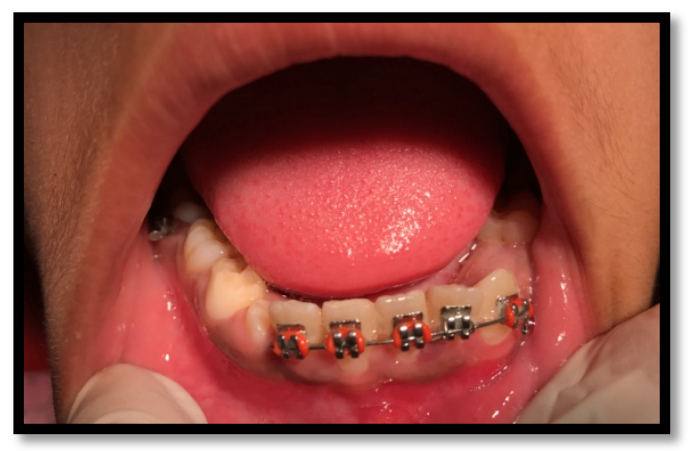

Figure 5: Photograph showing post-operative view after six months follow up

\section{DISCUSSION}

Canines are important for an attractive smile as it is the cornerstones of the dental arch and are also essential for a functional occlusion. Therefore, extraction of the impacted permanent canine is generally contraindicated. The diagnosis and localization of the impacted teeth is the most important step in the management of impacted teeth. However, bringing an unerupted or impacted permanent canine into the occlusion should not be the only goal in managing these teeth. The aim should be to attain proper occlusion, with a healthy zone of attached gingiva and ideal alveolar bone height.

Failure of eruption of the mandibular canine is an unusual event ${ }^{18}$. Mandibular canine impaction is regarded as a much rarer phenomenon and there are limited numbers of studies revealing its frequency of occurrence ${ }^{4}$. Grover and Lorton ${ }^{19}$ found only 11 impacted canines $(0.22 \%)$ in the mandible in 5000 individuals. $\boldsymbol{C h u}$ et $\boldsymbol{a l} .{ }^{20}$ reported five mandibular impacted canine $(0.07 \%)$ teeth in 7486 patients. A study by Rohrer $^{5}$ examining 3,000 patients radiographically found 62 impacted maxillary canines $(2.06 \%)$ and only three impacted mandibular canines $(0.1 \%)$,in a $20: 1$ ratio. In another study by Aydin et $\boldsymbol{a l}^{4}$ involving 4500 Turkish patients, the incidence of mandibular canine impaction was $0.44 \%$. Definitely, maxillary canine impaction is more frequent than is mandibular canine impaction ${ }^{3,4,21}$.

There are many reasons for the failure of tooth eruption, including inadequate space, supernumerary teeth, premature loss of deciduous teeth, retention of deciduous teeth, excessive crown length, hereditary factors, functional disturbance of endocrine glands, tumors, cysts, and trauma ${ }^{22-27}$. However, our patient had no apparent tumors, cysts, and dental trauma. Therefore, in this present case, we believed that the origin of the canine impaction was due to the ectopic eruption of lower left permanent canine.

The mandibular canines are affected by pathology in a lower ratio than the third molars and premolars $^{18,20}$. However, some authors reported few cases of dentigerous cyst, squamous odontogenic tumors, and ameloblastoma which were associated with impacted mandibular canine teeth ${ }^{26,27,28}$. But in our case no such pathologies were observed.

Most impacted teeth are asymptomatic, but chronic infection with fistula formation and some symptoms such as pain and swelling have been reported in the literature ${ }^{18,20}$. In our case the tooth was completely asymptomatic.

There are several treatment options proposed for impacted mandibular canines including surgical removal, exposure and orthodontic alignment, transplantation, and observation ${ }^{29}$. If adequate space for alignment of an impacted mandibular canine exists and it is mechanically possible to reposition an impacted mandibular canine into proper position, then orthodontic treatment is indicated $^{29,30}$. Following surgical exposure, the impacted tooth may be allowed to erupt passively, especially if it has a favourable angulation to erupt on its own. Alternatively, forced eruption may be carried out in conjunction with orthodontic alignment ${ }^{30,31}$.As a third alternative, if an impacted canine cannot be positioned favourably but there is space for its full eruption, then orthodontic treatment may help to align the adjacent teeth in their migrated order followed by crowning or recontouring of some teeth to improve esthetics ${ }^{32}$.

Orthodontic treatment is associated with soft and hard tissue changes, thus creation and maintenance 
of gingival and periodontal health is paramount to ensure optimal results. Although no specific dimensions of keratinized tissue have been indicated for maintenance of periodontal health, in orthodontic cases presence of keratinized tissue is important to prevent formation of periodontal defect ${ }^{33,34}$. Classically, three fundamental principles are considered when treating impacted teeth: the surgical approach, the type of fixation that is adhered to the tooth for its posterior traction and the orthodontic movements that have to be applied in order to position the tooth in the dental $\operatorname{arch}^{35,36,37}$.From a periodontal perspective, the appropriate surgical technique should allow the orthodontist to apply measured forces in a favourable direction for efficient correction of the impaction and for avoidance of damage to adjoining soft tissues and teeth ${ }^{33,34,35,38}$.

The orthodontic guidance of impacted canine may not be successful in all the cases; there may be failures, nonalignment of impacted canine in the desired position. The prognosis is worst in cases where canine is impacted horizontally and apically deep in palatal process ${ }^{39}$. The other factors known for failure include ankylosis of impacted canine, malformations of root, external resorption. Root resorption is reported to be more frequently in palatally impacted canine. An unexplained pain can be because of collision of crown of impacted canine with roots of adjacent teeth. If the impacted canine does not respond to the applied orthodontic force for 3 months, supplementary treatment plan has to be carried out ${ }^{40}$.

\section{CONCLUSION}

The management of impacted canines is important in terms of aesthetics and function. Clinicians must formulate treatment plans that are in the best interest of the patient and they must be knowledgeable about the variety of treatment options. When patients are evaluated and treated properly, clinicians can reduce the frequency of ectopic eruption and subsequent impaction of the maxillary canine.

Various surgical and orthodontic techniques may be used to recover impacted canines ${ }^{41}$. The proper management of these teeth, however, requires that the appropriate surgical technique be used and the clinician must be able to apply measured forces in a favourable direction. This allows for complete control in efficient correction the impaction and for avoidance of damage to adjacent teeth. Careful selection of surgical and orthodontic techniques is essential for the successful alignment of impacted canines.

\section{REFERENCES:}

1 Richardson G, Russel 1 KA. A Review of Impacted Permanent Maxillary Cuspids: Diagnosis andPrevention. J Can Dent Assoc 2000: 66:497501.

2 Rajic S, Muretic Z, Percac S. Impacted canine in a prehistoric skull. Angle Orthod 1996: 66:477-80.

3 D'Amico RM, Bjerklin K, Kurol J, Falahat B. Long-term Results of Orthodontic Treatment of Impacted Maxillary Canines. Angle Orthod 2003: 73:231-238.

4 Aydin U, Yilmaz HH, Yildirim D. Incidence of canine impaction and transmigration in a patient population. Dentomaxillofac Radiol 2004: 33:1649.

5 Rohrer A. Displaced and impacted canines. Int J Orthod Oral Surg 1929: 15:1003.

6 Mead SV. Incidence of impacted teeth. Int J Orthod Oral Sur 1930; 16: 885-890.

7 Yavuz MS, Aras MH, Büyükkurt MC, Tozoglu S. Impacted mandibular canines. J Contemp Dent Pract 2007; 8: 78-85.

8 Sham RM, Boyd MA, Vakil TF. Studies of permanent tooth anomalies in 7,886 Canadian individuals. J Can Dent Assoc 1978; 44: 262-264.

9 Brown LH, Berkman S, Cohen D, Kaplan AL, Rosenberg M. A radiological study of the frequency and distribution of impacted teeth. J Dent Assoc S Afr 1982; 37: 627-630.

10 Vichi M., Franchi L. Eruption anomalies of the maxillary permanent cuspids in children with cleft lip and or palate. J Clin Pedia Dent 1996; Vol 20:149-53.

11 Mc Connelt. L., Hoffman D.L., Forbes D.P., Janzen E.K., Weintraub N.H. Maxillary canine impaction in patients with transverse maxillary deficiency. J dent Child 1996;63:190-195.

12 Sasakura H., Xoshida T., Murxama S., Hamadak., Makajima T. Root resorption of upper permanent incisor caused by impacted canine. An analysis of 23 cases. Int J Oral Surg 1984; Vol 13:299-306.

13 Ericson S, Kurolj. Radiographic examination of ectopically erupting maxillary canines. Am J Orthod Dentofac Orthop 1987, Vol 91:483-492.

14 Peck S., Peck L., Katajam. Site specificity to tooth agenesis in subjects with maxillary canine malpositions. Angle Orthodontist 1996; Vol 66:473-476.

15 Goho C. Delayed eruption due to overlying fibrous connective tissue: case reports. J Dent Child 1987; Vol 54:359-360.

16 Benoit R., Leduc J.P., Genon P. Considérations orthodontiques et parodontales pour la miseen place des canines en bordure des fentes labioalvéolaires. J Parodont 1989; Vol 8:139-154.

17 Farid Bourzgui, Mourad Sebbar, Zouhair Abidine and Zakaria Bentahar. Management of Dental Impaction.Orthodontics - Basic Aspects and Clinical Considerations.

18 Camilleri S, Scerri E. Transmigration of mandibular canines-A review of the literature and a 
report of five cases. Angle Orthod 2003: 73:753762.

19 Grover PS, Lorton L. The incidence of unerupted permanent teeth and related clinical cases. Oral Surg Oral Med Oral Pathol 1985: 59:420-425.

20 Chu FCS, Li TKL, Lui VKB, Newsome PRH, Chow RLK, Cheung LK. Prevalence of impacted teeth and associated pathologies - a radiographic study of the Hong Kong Chinese population. Hong Kong Med J 2003: 9:158-163.

21 Alaejos-Algarra C, Berini-Aytes L, Gay-Escoda C. Transmigration of mandibular canines: Report of six cases and review of the literature. Quintessence Int. 1998: 29:395-398.

22 Joshi MR. Transmigrant mandibular canines: a record of 28 cases and a retrospective review of the literature. Angle Orthod 2001; 71: 12-22.

23 Tanaka E, Kawazoe A, Nakamura S, Ito G, Hirose N, Tanne Y, Kawai N, Tanimoto K,Tanne K.An adolescent patient with multiple impacted teeth.Angle Orthod 2008; 78: 1110-1118.

24 Taguchi Y, Kurol J, Kobayashi H, Noda T. Eruption disturbances of mandibular permanent canines in Japanese children. Int $\mathbf{J}$ Paediatr Dent 2001; 11: 98-102.

25 Fujita Y, Takahashi T, Maki K. Orthodontic treatment for an unerupted and severely rotated maxillary central incisor. A case report. Eur J Paediatr Dent 2008; 9: 43-47.

26 Monteil RA, Terestri P. Squamous odontogenic tumor related to an unerupted lower canine. J Oral Maxillofac Surg 1985; 43: 888-895.

27 Liposky RB. Decortication and bone replacement technique for the treatment of a large mandibular cyst. J Oral Surg 1980; 38: 42-45.

28 El-Hakim IE, El-Khashab MM. Peripheral and Mural Ameloblastoma in the mandibular canine region of a 13-year-old boy. J Oral Maxillofac Surg 2000: 58:1150-115.

29 McDonald F, Yap WL. The surgical exposure and application of direct traction of unerupted teeth. Am J Orthod. 1986: 89:331-40.
30 Ferguson JW. Management of the unerupted maxillary canine. Br Dent J. 1990: 169:113-114.

31 Bishara SE. Impacted maxillary canines. Am J Orthod Dentofac Orthop 1992: 101:159-71.

32 Shanmuhasuntharam P, Boon LC. Transmigration of permanent mandibular canines. Case report. Aust Dent J. 1991: 36:209-213.

33 Borbély P, Watted N, Dubovská I, Hegedüs V, Muhamad AH; Interdisciplinary Approach In The Treatment Of Impacted Canines, Int J Maxillofac Res. 2015: 1(2); 116-137.

34 Abu-Hussein M, Watted N, Abdulgani M, Abdulgani Az (2016) Tooth Autotransplantation; Clinical Concepts. Journal of Dental and Medical Sciences 15: 105-113

35 Prato GP, Baccetti T, Magnani C, Agudio G \& Cortellini P: Mucogingival interceptive surgery of buccally-erupted premolars in patients scheduled for orthodontic treatment. I. A 7- year longitudinal study. J periodontol 2000; 71:172-181.

36 Abu-Hussein M, Watted N, Emodi O, Obaida Awadi (2015) management of lower second premolar impaction. Journal Of Dental College Azamgarh 1: 71-79.

37 Watted N, Abu-Hussein M (2016) Dental Transposition of Mandibular Canine and Lateral Incisor. J Dent Probl Solut 3(1): 045-049. DOI: 10.17352/2394-8418.000034

38 Johnston WD. Treatment of palatally impacted canine teeth. Am J Orthod 1969; 56:589-96.

39 McSherry PF. The assessment of and treatment options for the buried maxillary canine. Dent Update 1996; 23: 7-10.

40 Ericson S, Kurol J. Radiographic examination of ectopically erupting maxillary canines. Am J Orthod Dentofac Orthop1987; 91: 483-92.

41 Patel S. Alignment of impacted canines with cantilevers and box loops. J Clin Orthod. 1999;33:82-5 